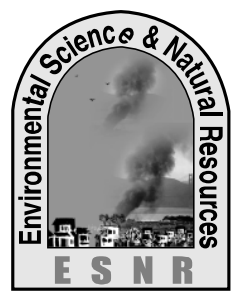

J. Environ. Sci. \& Natural Resources, 7(1): 149-156, $2014 \quad$ ISSN 1999-7361

\title{
Impact of Tanneries Waste Disposal on Environment in Some Selected Areas of Dhaka City Corporation
}

\author{
S. H. Tinni, M. A. Islam, K. Fatima and M. A. Ali
}

Department of Environmental Science, Bangladesh Agricultural University

\begin{abstract}
The study was carried out to assess the awareness of peoples on the impact of tannery waste disposal on environmental pollution of selected areas in Dhaka City. Data were collected by interviewing 300 peoples randomly of which 90 were labor, 60 livestock farmers, 60 fishermen and 90 were in local people in the study areas. Data were collected on age, education level, occupation, type of waste, color of waste, waste disposal time, environmental effect, human diseases, environmental pollution awareness, livestock diseases, livestock production and fisheries production. The findings revealed that about $34 \%$ respondents were illiterate. Both solid and liquid waste $(56 \%)$ was come out from the tannery of which half of them were black in color. About $45 \%$ respondents were reported that the most environmental effect was bad smell to the surrounding areas. Survey result also showed different health problems such as skin diseases, itch, rash, cough, fever, diarrhea, headache, asthma, dizziness etc due to unplanned tannery waste disposal. The highest proportion (38\%) of respondents had low environmental pollution awareness due to their education level. Livestock and poultry were died due to tannery waste indicated by $59 \%$ respondents. The livestock and fish production was low, reported by $48 \%$. Education, occupation and type of waste had significant positive relationship where color of waste had no relationship with their environmental pollution awareness. The results of this study will be helpful to create people's awareness on environmental pollution and their impact by tannery waste disposal.
\end{abstract}

Key words: Awareness, Environmental impact, Tannery waste disposal.

\section{Introduction}

Leather industry plays an important role in Bangladesh Economy due to its large potential for employment, growth and export. At the same time, it poses serious environmental threats by discharging liquid effluents and solid wastes directly into surrounding low lying areas without proper treatment.Industrial wastes are major sources of pollution in all environments which require onsite treatment before discharge into sewage system (Emongor et al., 2005). In Bangladesh, there is a progressive increase in industrial wastes and due to rapid industrialization such waste products have been causing severe contamination to the air, water and soils thus pollutes the environment (Islam et al., 2000). The DoE recently identified 900 large polluting industries, which have no treatment facilities for effluent and wastes(DoE, 2001). These heavily toxic effluents were discharging directly to adjacent soils and rivers (Khan, 2006). Among all the industrial wastes tannery effluents are ranked as the highest pollutants (Azom et al., 2012).

Hazaribag, Rayerbazar and Islambag are important industrial areas of Dhaka city. Many tannery industries have been developed in these areas. The tanneries of Hazaribag started their journey from 1960. The industries expanded and after the independence of Bangladesh in 1971(Azom et al., 2012) . The Hazaribagh area in Dhaka was selected because of its long history of widely known untreated discharge of chromium based tanning effluents (Gain, 2002). About 200 tons of solid waste is generated per day during peak season and 75 tons during off-peak season from the tanneries of Hazaribag (Huq, 1990).

Around 20,000 peoples are presently living in the slums in the study area, under extremely densely populated and unhygienic conditions (Zahir and Ahmeduzzaman, 2012). Dhaka city is situated mainly in the Buriganga river and secondly the Turag River. The rivers are very much polluted by the tannery wastes. During last decade the livestock production and fish culture are seriously affected by the industrial waste specially tannery waste (BBS, 2009). For this reason a survey work is to be done. The present study aims at investigating the impacts of tannery waste disposal on water, soil and agricultural productivity.

Thus the present study was undertaken to achieve the following objectives:

i. To explore the present situation of the tannery surrounding environment.

ii. To characterize the tannery industry effluents.

iii. To promote environmental awareness of population.

\section{Materials and methods}

The study was conducted at Hazaribagh area under Hazaribagh thana, Rayerbazar area under Mohammadpur thana and Islambag area under Lalbag thana in Dhaka city corporation. Hazaribagh area 
were selected purposefully because Hazaribagh area is covered $90 \%$ of total tannery where high amount of tannery waste are dispose on surrounding area specially the Buriganga river. The Rayerbazar area and the Islambag area were also selected because of those area also polluted by tannery waste.

Primary data were used for this study. Sample survey was carried out for generating the required data. Three hundred respondents were interviewed from the study area and different information (secondary data) was collected with the help of Bangladesh bureau of statistics, Department of fisheries and Department of livestock. Three hundred respondents were randomly selected from three areas of which 90 were labors, 90 were local people, and 60 were fishermen and hatchery labor and 60 were livestock farmers. The maximum number of respondents from Hazaribagh selected for interview than other two areas. An interview schedule was prepared for collection of data from the respondents keeping the objectives of the study in mind. Both open and closed formed questions were included in the interview schedule. The questionnaire was prepared in Bengali for the respondents. Necessary additions, deletions, modifications and adjustments were made in the interview schedule on the basis of experience gained from the pretest. The pretest was helpful in identifying faulty questions and statements. The interview schedule was then finalized for collection of data. Personal observation and telephone interview were conducted for this study area.

To build rapport and motivation in the interview situations, the researchers endeavored to provide conditions that maximized trust, maintained each respondent's interest and minimize status difference. However, it is not possible to collect data from all labors, local people and fisherman and hatchery labors and livestock farmers in those areas due to their non-availability in the time of interview despite several attempts to contact them. Therefore the researcher had to collect data from 300 labor, local people, fisherman and hatchery labor and livestock farmers. Data were collected from January to May 2013.

Data were collected on age, educational qualification, occupation, type of waste, color of waste, waste disposal time, environmental effect, human diseases, environmental pollution awareness, effect of livestock, diseases of livestock, effect on livestock production, effect of fisheries and effect on fisheries production, individual characteristics of the respondents were considered as independent variable and environmental pollution awareness was considered as dependent variable. The data were analyzed by the SPSS (Statistical Package for Social Science) program, using cross tab to find out the \% of total data, mean, standard deviation and correlation between two or more variables.

\section{Result and discussion}

Three hundred (300) respondents like labor, fisherman, livestock farmer, local people at Hazaribagh, Rayerbajar and Islambag thana in Dhaka city were surveyed to find their perception about the impact of tannery waste on environmental pollution.

Characteristics of the diffeerent respondents are shown in Tables 1, 2 and 3.

Table 1: Distribution of respondents according to their age

\begin{tabular}{|c|c|c|c|c|}
\hline Age group & Frequency of respondents & \% Total & Mean & \multirow{2}{*}{ SD } \\
\hline Young ( 18-30) & $\mathbf{6 3}$ & 21 & \multirow{2}{*}{40.56} & \multirow{2}{*}{12.33} \\
\cline { 1 - 3 } Middle age (31-50) & $\mathbf{2 1 0}$ & 70 & & \\
\hline Old (>50) & $\mathbf{2 7}$ & 9 & & \\
\hline Total & $\mathbf{3 0 0}$ & 100 & & \\
\hline
\end{tabular}

Table 2: Distribution of respondents according to education level.

\begin{tabular}{|l|c|c|c|c|}
\hline \multicolumn{1}{|c|}{ Education level } & Frequency of respondents & \% Total & Mean & SD \\
\hline Illiterate & 102 & 34 & \multirow{3}{*}{2.61} & \multirow{2}{*}{1.03} \\
\cline { 1 - 3 } Primary level & 93 & 31 & \\
\cline { 1 - 3 } Secondary level & 51 & 17 & \\
\cline { 1 - 3 } Higher level & 54 & 100 & & \\
\cline { 1 - 3 } Total & 300 & & \\
\hline
\end{tabular}


Table 3: Distribution of respondents according to their occupation.

\begin{tabular}{|c|c|c|c|c|}
\hline Occupation & Frequency of respondents & \% Total & Mean & SD \\
\hline Fisherman & 60 & 20 & & \\
\hline Livestock farmer & 60 & 20 & & \\
\hline labor of tennery Industry & 90 & 30 & & \\
\hline Student & 24 & 8 & $\mathbf{3 . 0 4}$ & $\mathbf{1 . 4 6}$ \\
\hline Hous wife & 15 & 5 & & \\
\hline Others & 51 & 17 & & \\
\hline Total & 300 & 100 & & \\
\hline
\end{tabular}

\section{Types of waste}

About 15\% solid waste comes out from studied tanneries which are almost half of liquid waste (29\%). According to respondent's opinion maximum amount of wastes was the mixture of both solid and liquid materials. In the tanning process many chemicals such as Chromium oxide, ammonium sulfate, formic acid, sulfuric acid, sodium chloride etc are used which causes solid and liquid wastes (Gain, 2002). İn the processing of raw hide and skin the sulphuric acid and salt are used and then it was treated with the solutions of chromium salts. In the tannery chromium, HCl, Sulphuric acid, Formic acid, Caustic soda, Caustic potash, Soda ash, Sodium arsenite, Arsenic sulphite etc is used for different tanning process such as soaking, liming, deliming, tanning etc. (Khatun and Huq, 1994). At the end of every process the chemicals are washed by water which causes liquid waste. The major solid wastes generated by the tanneries are dusted curing salt, wet trimmings, dry trimmings, wet shaving, buffing, raw materials packing etc. gaseous emissions were observed by the researcher but no one respondents.

\section{Color of waste}

Survey result showed that the black color was discharge throughout the tannery was $47 \%$ which was maximum than other color. Mixed color waste discharge from tanneries was $39 \%$ which is second highest amount. Red and Blue colored waste were indicated by $7 \%$ respondents that very small relatively black and mixed. A research group (Nanda and Tiwari, 1999). observed that the quality of water deteriorates significantly after the discharge of industrial effluents into the river. Chrome tanning is the most common type of tanning where maximum amount of chromium is used. In the survey of blacksmith institute it was found that 20 percent large number of chemical is absorbed by leather others turn to the waste (Gain, 2002). The tannery is used different chemicals in tanning process. In a tannery industry 40 types of chemicals are used. At the end of leather processing those chemicals are washed. After washing these chemicals it turn into different colors. The waste comes out the tannery and runs through the drain and goes into the river and nearby ponds. The waste contain high amount of chemicals and for this reason the wastes are of many colors. So it showed that the maximum type of waste color is black. The blackish color tannery waste which discharged from the tannery is shown in the Fig. 1.

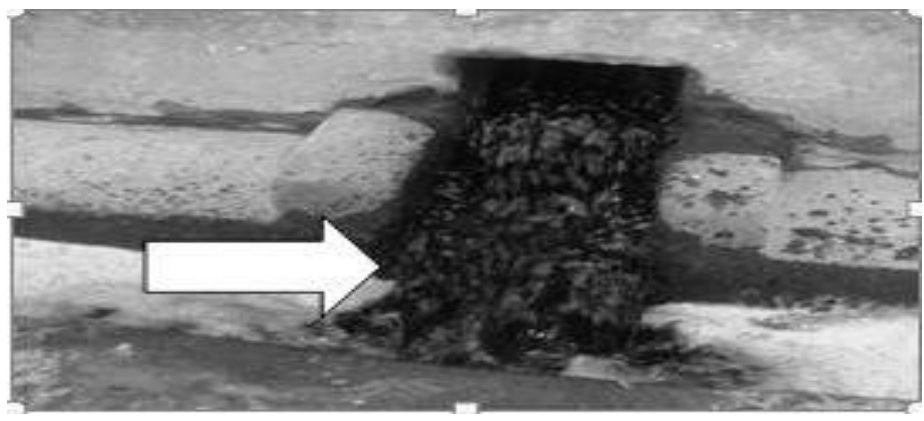

Fig. 1: Tannery waste run out from the unplanned tannery industry. Arrow indicates black waste discharge from the tannery 


\section{Environmental effect by tannery waste}

Survey result showed that the most environmental effect was bad smell to the surrounding area, indicated by respondents of $45 \%$ and the secondly scarcity of fresh water was $32 \%$ among the respondents. About 40 heavy metal and acid are used in the processing of raw hides (UNIDO, 2005). In the report of Blacksmith institute $20 \%$ of the large number of chemicals used in the tanning process is absorbed by leather, the rest was released as waste. Due to lack of proper management facilities the tannery waste create environmental pollution day by day (Azom et al., 2012). Pollution of environment is one of the most horrible ecological crisis to which we are subjected today. About $95 \%$ of the tannery industries have been built in unplanned way at the congested places of my survey area during the last fifty years. These unplanned tanneries caused environmental pollution very much. It was showed that the most harmful environmental effect was bad smell to the surrounding areas which caused environmental pollution.

\section{Human diseases}

It was found that the highest portion $(33 \%)$ of the respondents caused skin diseases by spreading of waste in water and soil, compared to $18 \%$ of the respondents caused by skin diseases, rash, and itch (Table 4). Huge amounts of chemicals flow off the tannery floor, into open gutters in those areas streets, and then into a stream leading to the Buriganga and the turag which are the main rivers of Dhaka. Over 8,000 workers in the tanneries of Hazaribag suffer from gastrointestinal, dermatological, and other diseases, and $90 \%$ of this population dies before the age of 50 (Human Rights Watch, 2012). The presence of arsenic in the ground water increasing scarcity of fresh drinking water which causes skin lesion, kidney, liver complication, cancer etc. (Breckle and Khale, 1992). In the author's survey found that most of the respondents suffer from skin diseases. The tannery labors did not wear any gloves, apron and special shoes rather than they work in bare feet. The tannery wastes were disposed in unplanned way. These wastes were fall in the nearby river and the slums people use these water which causes various diseases to them (Fig. 2). These wastes covered the surrounding area which creates foul smelling. The foul smelling environment damagedhuman health.

\section{Environmental pollution awareness}

The highest proportion (38\%) of respondents had low environmental pollution awareness where $27 \%$ of the respondents had no knowledge in environmental pollution. The data indicated that $17 \%$ of the respondents in the study area comprised of medium awareness category about environmental pollution. About $18 \%$ of the respondents showed their high environmental pollution awareness. In the survey area the maximum respondents were low environmental pollution awareness. The maximum respondents were live in the slum. The slums people were very poor. The resident of the slums were used in dirty water for various purposes. The environment inside the tanneries was unwholesome.

\section{Effect on livestock sector}

Survey result showed the list of the effect of livestock sector that was reported by the respondents. It was found that the highest portion of respondents $(44 \%)$ difficulty water problem by spreading of waste in water and soil, compared to mortality, movement problem and fodder toxicity during the tannery waste (Table 5)

Table 4: Distribution of respondents according to the effect of livestock sector.

\begin{tabular}{|c|c|c|c|c|}
\hline Effect of livestock sector & Frequency of respondents & $\%$ Total & Mean & SD \\
\hline Fodder toxicity & 24 & 8 & \multirow{6}{*}{3.07} & \multirow{6}{*}{1.09} \\
\hline Movement problem & 30 & 10 & & \\
\hline Water problem & 132 & 44 & & \\
\hline Mortality & 99 & 33 & & \\
\hline All & 15 & 5 & & \\
\hline Total & 300 & 100 & & \\
\hline
\end{tabular}




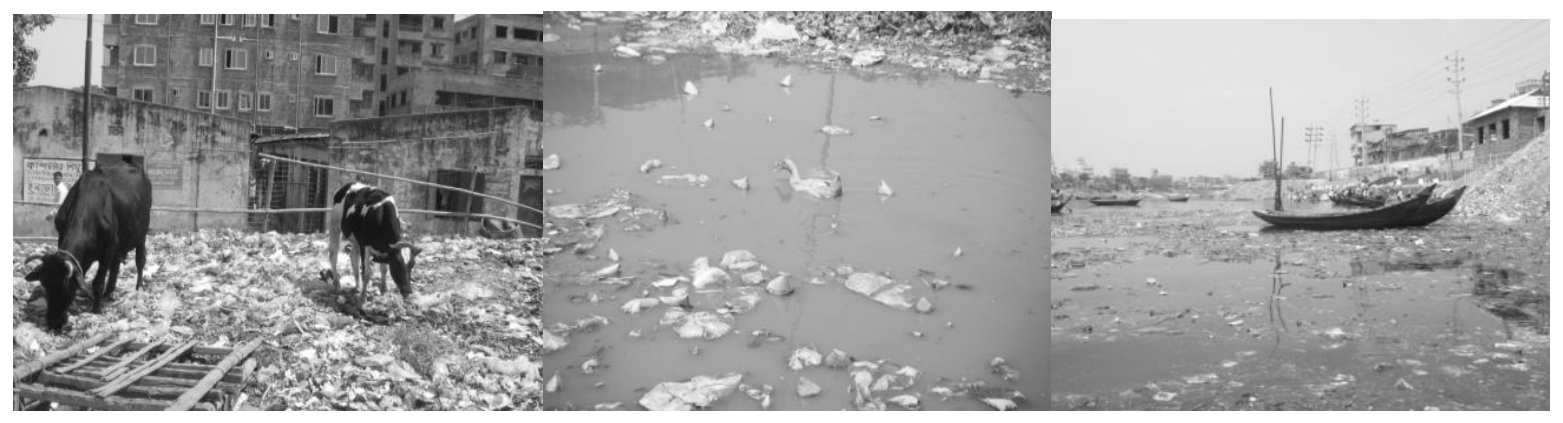

Fig. 2: Showing unplanned dumping of the solid and liquid tannery wastes.

\section{Livestock diseases}

Respondents said that they are tried to save their livestock from these waste but they cannot do that. In the survey it is shows that maximum diseases of livestock's are died.

Table 5: Distribution of respondents according to the livestock's diseases.

\begin{tabular}{|c|c|c|c|c|}
\hline Livestock diseases & Frequency of respondents & $\%$ Total & Mean & SD \\
\hline Livestock/ poultry die & 177 & 59 & \multirow{4}{*}{1.51} & \multirow{4}{*}{0.50} \\
\hline Livestock/poultry skin diseases & 120 & 40 & & \\
\hline Other diseases & 3 & 1 & & \\
\hline Total & 300 & 100 & & \\
\hline
\end{tabular}

\section{Effect on livestock production}

The effect of livestock production was low reported by half of the respondents $(48 \%)$. Secondly the effect of livestock production was very low which was indicated by $45 \%$. So, the tannery waste was harmful to livestock production in sutdy area. In the survey area the livestock farm is decreasing drastically due to the disposal of tannery wastes. The solid wastes are dumped in open places (Fig. 2). The liquid wastes are discharged in unplanned way. The livestock eat these wastes and attack by various diseases.

\section{Effect on fisheries sector}

It was found that the highest portion of respondents $(58 \%)$ said that the effect of fisheries sector was mortality compared to stunted growth (10\%) and both effect $(32 \%)$ by spreading of waste in water. The direct discharge of these wastes has contaminated the ground and surface water with dangerously high concentrations of chromium, as well as cadmium, arsenic, and lead. The contamination of rivers also allows these pollutants to accumulate in common fish and shellfish species, which are used as local food sources (Huq, 1990). The polluted water is harmful for aquatic life reported in (Zahir and Ahmeduzzaman, 2012). Due to tannery waste the aquatic resources were adversely affected and fish production was drastically reduced. The wastes which contain high amount of chemical especially chromium are fall in the river which is very much harmful to fish and aquatic plants (Breckle and Khale, 1992). The fishes were eating the disposed waste and died. In the survey it was showed that maximum bad effect occurred by tannery waste in fisheries sector is fish mortality.

\section{Effect on fisheries production}

The effect of fisheries production was very low and that was $50 \%$. Secondly the effect of fisheries production was low which reported by $43 \%$ and others are the medium effect which reported by $7 \%$ respondents. The tannery wastes were harmful to fisheries production. In survey area the fish was decreasing day by day due to the unplanned disposal of tannery wastes. The liquid wastes were discharged into the open canal followed by river without any treatment. These wastes were disposed on the the river of Buriganga and Turag. The fishes were eating these wastes. The hatchery farmer's objected that in the rainy season the tannery waste comes in this hatchery and fishes are died. So the fish production is adversely hampered due to tannery wastes.

\section{Effect on the agricultural production}


The tannery waste affected the agricultural production very much. In survey work, the respondents reported during interview that the agricultural land which is now unsuitable for agricultural production. The respondents showed some land where agricultural production was cultivated in 10 years ago. But now those lands were not suitable for cultivation.

\section{Relationship between the selected characteristics of the respondents and environmental pollution awareness}

This section deals with the relationship of the 4 selected characteristics of the respondents in the study area. The selected characteristics of the respondents are constituted independent variable and the dependent variable is the environmental pollution awareness of the respondents in the study area. Summary results of the correlation co-efficient (r) between the selected characteristics of respondents and environmental pollution awareness of the respondents has been presented in Table 7.

Table 6: Relationship between Environmental Pollution Awareness and other selected characteristics (N=300).

Dependent variable

Environmental pollution awareness

$* * *=$ Correlation is significant at $0.001 \%$ level of probability

Independent variable

Education

Occupation

Waste type

Waste color
NS $=$ Not significant

\section{Relationship between Education level and Environmental Pollution Awareness}

The relationship between education level of the respondents and their environmental pollution awareness was examined by testing the null hypothesis: "there is no relationship between education level of the respondents and their environmental pollution awareness". The computed value of the coefficient of correlation between education level and environmental pollution awareness was found to be 0.90 shown in Table 7 . Based on the coefficient value, the following observations were made, like- a) the relationship showed a positive trend, b) a significant relationship was found between two variables at 0.001 level of probability. The educational qualification is highly significant on environmental pollution awareness. The illiterate person had no environmental pollution awareness. Based on the above findings, the null hypothesis was rejected.

\section{Relationship between occupation and Environmental Pollution Awareness}

The relationship between occupation of the respondents and their environmental pollution awareness was examined by testing the null hypothesis: "there is no relationship between occupation of the respondents and their environmental pollution awareness". The computed value of the coefficient of correlation between education and environmental pollution awareness was found to be 0.786 shown in table 6 . Based on the
Computed value of ' $r$ '

Level of significant $(\%)$

$\begin{array}{cc}0.90^{* * *} & 0.001 \\ 0.786^{* * *} & 0.001 \\ 0.960^{* * *} & 0.001 \\ 0.101^{\mathrm{NS}} & \mathrm{NS}\end{array}$

coefficient value, the following observations were made, like- a) the relationship showed a positive trend, b) a significant relationship was found between two variables at 0.001 level of probability.The occupation and environmental pollution awareness is highly significant. Based on the above findings, the null hypothesis was rejected.

Relationship between Type of waste and Environmental Pollution Awareness

The relationship between type of waste of the respondents and their environmental pollution awareness was examined by testing the null hypothesis: "there is no relationship between type of waste of the respondents and their environmental pollution awareness". The computed value of the coefficient of correlation between type of waste and environmental pollution awareness was found to be 0.96 as shown in Table 7 . Based on the coefficient value, the following observations were made, like- a) the relationship showed a positive trend, b) a significant relationship was found between two variables at 0.001 level of probability. In tanning process most of the chemicals used which creates solid and liquid waste (Breckle and Khale, 1992). In this survey, it was found positive relationship. Based on the above findings, the null hypothesis was rejected.

Relationship between Color of waste and Environmental Pollution Awareness 


\section{J. Environ. Sci. \& Natural Resources, 7(1): 149-156, $2014 \quad$ ISSN 1999-7361}

The relationship between color of waste of the respondents and their environmental pollution awareness was examined by testing the null hypothesis: "there is no relationship between color of waste of the respondents and their environmental pollution awareness". The computed value of the coefficient of correlation between color of waste and environmental pollution awareness was found to be 0.101 as shawon in Table 7 . Based on the coefficient value, the following observations were made, such asa) the relationship showed a positive trend, and b) insignificant relationship was found between two variables. Based on the above findings, the null hypothesis was accepted.

\section{Conclusion}

The study describes the relationship between environmental pollution awareness and others parameters like age, education level, profession, agricultural production etc. According to respondent's opinion maximum amount of wastes was the mixture of both solid and liquid materials. Survey result showed that the waste disposed in noon than morning and afternoon. The most environmental effect was bad smell to the surrounding area, and the secondly scarcity of fresh water. Different types of health problems occurred in the study area according to respondent's opinion. Highest proportion of respondents had low environmental pollution awareness where one-third of the respondents had no knowledge in environmental pollution. Tannery waste affects the livestock sector. It was found that the highest portion of respondents faced in difficulty related to water problem compared to mortality, fodder toxicity. Various livestock's diseases occurred by tannery wastes. Tannery wastes are harmful for livestock production. The high portion of respondents indicates the livestock production is low. The tannery waste causes the harmful effect on fisheries sector also. Fish production is decreasing day by day due to unplanned disposal of tannery wastes. Correlation analysis indicates that education, occupation and type of waste used by the respondents had significant positive relationship with their environmental pollution awareness. Hence the concerned null hypotheses were rejected by the researcher.

In the study it is demonstrated that mostly all the stages of tannery processing, individually and collectively impacts negatively to the environment. Results revealed that tanning industry wastes poses serious environmental impact on air, water and soil pollution, human, fish and livestock diseases. It is expected that the research findings would be applicable in general to the peoples as well as labor of tannery industry, respondents who lives nearby the tanner industry, livestock farmer and fisherman. The peoples should be educated to be perceived the probable impact on the tannery waste disposal towards the health and environment. Finally, it could be said that adequate preventive measures should be taken in tannery industrial activities with a view to ensuring safe, sound and healthy environment for greater benefit of Bangladesh.

\section{References}

Azom, M.R.; Mahmud, K.; Yahya, S.M.; Sontu, A. and Himon, S.B. 2012. Environmental Impact Assessment of Tanneries: A case study of Hazaribagh. Bangladesh Journal of environmental impact, 3: 152-156.

BBS (Bangladesh Bureau of Statistics). 2009. Report of Health and Demographic Survey, Bangladesh Bureau of Statistics, Ministry of Health and Family Welfare, Dhaka, Bangladesh. P. 15.

Breckle, S.W. and Khale, H. 1992. Effect of toxic heavy metals $(\mathrm{Cd}, \mathrm{Pb})$ on growth and mineral nutrition of beech (Fagussylvatica L.). Vegetatio, 101: 43-53.

Department of Environment (DoE), 1991. Bangladesh, State of the Environment, Dept. Environ. and Ministry of Environ. and Forest. Pub. UNEP.P.O Box-4, Klong, Luang, Pathaumthani, 12120, Thailand. Pp. 12-22.

Gain, P. 2002. Bangladesh Environment: Facing the 21st century, Society for Environment and Human Development (SEHD), Dhaka, Bangladesh, Pp. 12-18.

Human, R. W. 2012. Toxic Tanneries: The Health Repercussions of Bangladesh's Hazaribagh Leather, October. Pp. 6-14 \& 20-55.

Huq, I. 1998. Critical Environmental Issues Relating to Tanning Industries in Bangladesh. In: Naidu et al. (eds), Towards Better Management of Soils Contaminated with Tannery waste. The Proceedings of a workshop, Tamil Nadu Agricultural University, Coimbatore, India, P. 5.

Islam, M.R.; Lahermo, P.; Salminen, P.; Rojstaczer, S. and Peuraniemi, V.2000. Lake leaching from tropical soils. Bangladesh Environmental Geology, 39: 1083-1089. 
Khan, H.R. 2006. Assessment of SPWAC (Soil-PlantWater-Air Continuum) Quality within and around Dhaka city. Report submitted to the Director of the Centre for Advanced Studies and Research in Biotechnological Sciences, University of Dhaka, Bangladesh. P. 127.

Khatun, H. and Huq, M. 1994. Paribeshdusholleyhazaribaghelkarchamrashilp a (Leather industries in the Hazaribagh area and environmental pollution). Bhugole Patrika (Geography Journal), 13: 8- 19.

Nanda, S.N. and Tiwari, T.N. 1999. Effect of discharge of industrial effluents on the quality of river Brahmani at Rourkela. Indian $J$. Environ. prot., 19: 52-55.

UNIDO (United Nations Industrial Development Organization). 2005. Cost of Tanned Waste Treatment. 15th Session of the Leather and Leather Products Industry Panel. Leon. Mexicom, 17-18.

Emongor, V.; Nkegbe, E.; Kealotswe, B.; Koorapetse, I.; Sankwasa, S. and Keikanetswe, S. 2005. Pollution Indicators in Gaborone Industrial Effluent. Journal of Applied Sciences, 5: 147150.

Zahir, H.; Ahmeduzzaman, M. 2012. A case study on the impact of leather industries on the ground water aquifer in Bangladesh. International Journal of Civil \& Environmental Engineering IJCEE-IJENS, 12: 5254. 